\title{
First Cool-Down Performance of the LHD
}

Toshiyuki Mito, Ryuji Maekawa, Shuichi Yamada, Arata Nishimura, Kazuya Takahata, Akifumi Iwamoto, Shinsaku Imagawa, Kiyomasa Watanabe, Nagato Yanagi, Hitoshi Tamura, Tomosumi Baba, Sadatomo Moriuchi, Kouki Oba, Haruo Sekiguchi, Isao Ohtake, Takashi Satow, Sadao Satoh, Osamu Motojima and LHD Group

National Institute for Fusion Science, Oroshi, Toki, Gifu 509-5292, JAPAN

\begin{abstract}
The first cool-down test of the Large Helical Device (LHD) and the performance of the LHD cryogenic system during the first cycle operation are described. The first cool-down started on Feb. 23, 1998 and finished on Mar. 22. After the cool-down, the excitation tests of the SC coils up to 1.5 $\mathrm{T}$ and the first cycle operations for plasma physics experiments were conducted until May 18. The first cycle operation was successfully completed after the warm-up process to the room temperature from May 19 to Jun. 15. The cooling characteristics of the LHD, such as temperature distribution during cool-down, heat loads under steady state condition, reliability during long-term operation, are reported.
\end{abstract}

\section{INTRODUCTION}

The LHD is the first fully superconducting heliotron type experimental fusion device [1]. The superconducting coils for the LHD consist of two helical coils ( $\mathrm{H} 1$ and $\mathrm{H} 2)$ and three pairs of poloidal coils (IV, IS and OV). The helical and poloidal coils are mounted on the supporting structure in the cryostat. The construction of the LHD started in 1991 and finished at the beginning of 1998. The construction of the He refrigerator was completed at the end of FY 1994. The cooling capacities of the He refrigerator $(5.65 \mathrm{~kW}$ at $4.4 \mathrm{~K}$, $20.6 \mathrm{~kW}$ from $40 \mathrm{~K}$ to $80 \mathrm{~K}$ and $650 \mathrm{~L} / \mathrm{h}$ liquefaction, simultaneously) were confirmed by a series of commissioning runs in 1995 [2]. Then the test operations of the $\mathrm{He}$ refrigerator were conducted with a dummy load, which could simulate the heat load for the LHD [3].

\section{LHD CRYOGENIC SYSTEM}

\section{A. Description of the LHD cryogenic system}

The LHD cryogenic system consists of the helium refrigerator/liquefier, the superconducting helical and poloidal coils, the supporting structure, the LHD cryostat, the control-valve-boxes, the superconducting bus-lines, the current-leads cryostat and the cryogenic transfer-lines, as shown in Fig. 1 [4].

Fig. 2 shows a cooling scheme of the LHD. The helium refrigerator/liquefier can support four different cooling methods; 1) pool boiling for the helical coils and the current leads, 2) forced-flow supercritical helium for the CICC poloidal coils, 3) forced-flow two phase helium for the supporting structure and the superconducting bus lines, 4) forced-flow $40 \mathrm{~K}-80 \mathrm{~K}$ helium gas for the $80 \mathrm{~K}$ radiation shields. The composition of the He refrigerator/liquefier is shown in Fig. 3.

Manuscript received September 15, 1998.

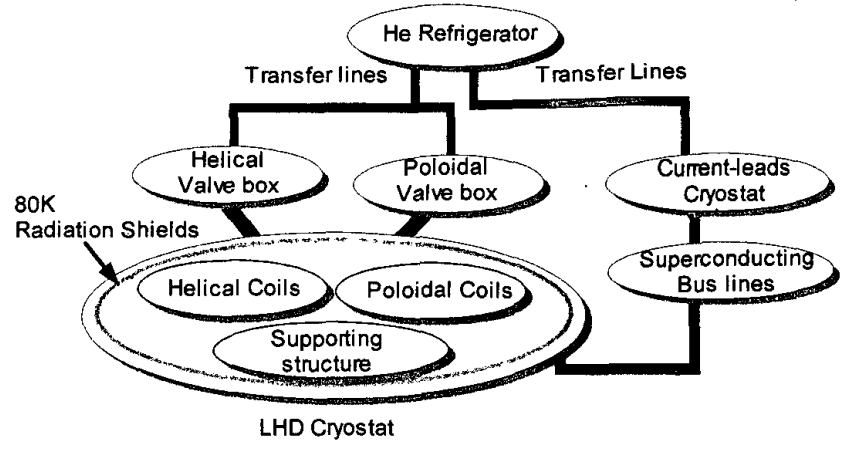

Fig. 1. Schematics of the LHD cryogenic system.

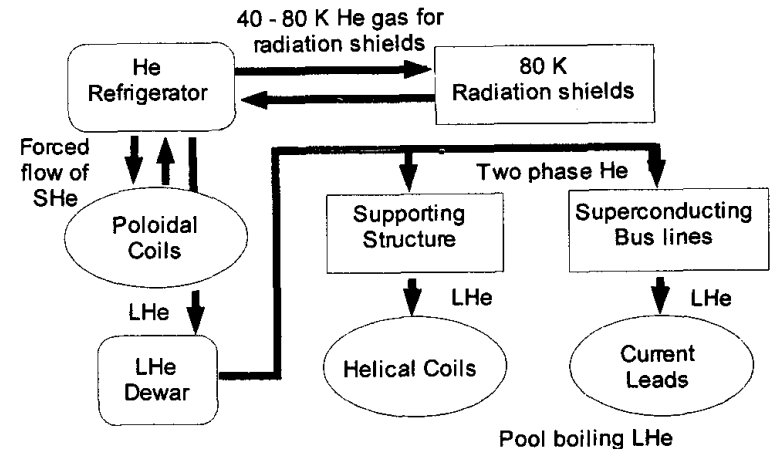

Fig. 2. Cooling scheme of the LHD.

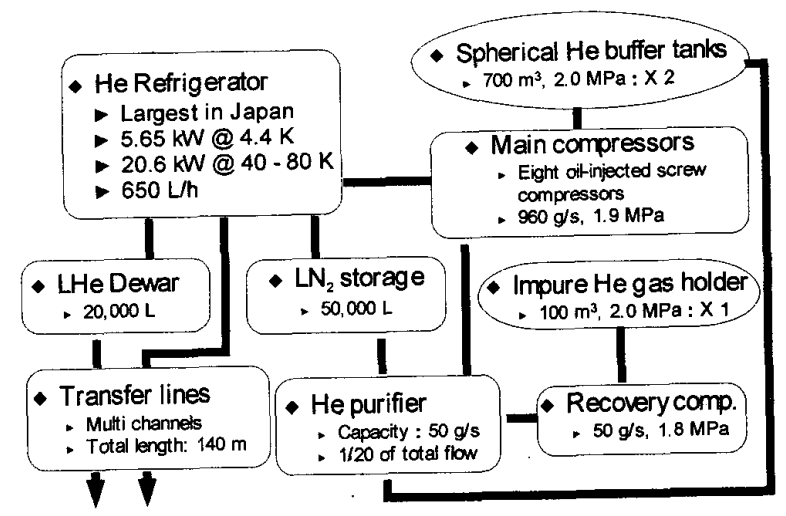

Fig. 3. Composition of the LHD He refrigerator/liquefier.

\section{B. Cool-down scenario}

We planed the first cool-down of the LHD from $300 \mathrm{~K}$ to $4.4 \mathrm{~K}$ as a 4-week procedure. The total cold mass in the LHD cryostat is estimated to be 856 tons, and its detail for each component is listed in Table 1 . The helical coils, 
TABLE 1. COLD MASS AND OPERATING TEMPERATURE

\begin{tabular}{|c|c|c|c|}
\hline \multirow[t]{2}{*}{ Items } & \multicolumn{2}{|c|}{ Cold mass } & \multirow{2}{*}{$\begin{array}{r}\text { Temp } \\
\text { (K) }\end{array}$} \\
\hline & (ton) & ratio & \\
\hline Helical coils & $77.5 \times 2=155$ & 0.181 & 4.4 \\
\hline Shell arms & $42.5 \times 2=.85$ & 0.099 & 4.4 \\
\hline Supporting structures & $(400)$ & $(0.467)$ & 4.4 \\
\hline Cooling path A & 100 & 0.117 & 4.4 \\
\hline Cooling path $B$ & 200 & 0.234 & 4.4 \\
\hline Cooling path $\mathrm{C}$ & 100 & 0.117 & 4.4 \\
\hline Poloidal coils & (182) & $(0.213)$ & 4.4 \\
\hline IV coils & $16 \times 2=32$ & 0.037 & 4.4 \\
\hline IS coils & $25 \times 2=50$ & 0.058 & 4.4 \\
\hline OV coils & $50 \times 2=100$ & 0.117 & 4.4 \\
\hline $4.4 \mathrm{~K}$ total & 822 & 0.960 & 4.4 \\
\hline Inner $80 \mathrm{~K}$ shield & 10 & 0.012 & 80 \\
\hline Outer $80 \mathrm{~K}$ shield & 13 & 0.015 & 80 \\
\hline Cryogenic post & 11 & 0.013 & 80 \\
\hline $80 \mathrm{~K}$ total & 34 & 0.040 & 80 \\
\hline $4.4 \mathrm{~K}+80 \mathrm{~K}$ total & 856 & 1.000 & \\
\hline
\end{tabular}

the poloidal coils and the supporting structures are cooled simultaneously to reduce the thermal stress caused by the temperature difference in each component. The $80 \mathrm{~K}$ shields of the LHD cryostat are also cooled with the coils and the supporting structure until the supply gas temperature goes down to $80 \mathrm{~K}$. The cooling flow of the LHD has many parallel paths as shown in Fig. 4. The temperature controlled cold gas is distributed to each component according to its cold mass. The total mass flow varies from $100 \mathrm{~g} / \mathrm{s}$ to 550 $\mathrm{g} / \mathrm{s}$ depending on the temperature. Therefore, the mass flow rate for each component was controlled by giving the set value calculated from the ratio of mass flow rate out of the total mass flow rate.

\section{First cycle operation of the LHD}

\section{A. Progress of the first cycle operation}

Main events during the first cool-down test are listed in Table 2. We started the main compressors on Feb. 9, 1998, and continued purifying operation of the cryogenic system until Feb. 22 to remove impurities in helium gas (such as oxygen, nitrogen, water, etc.) less than $2 \mathrm{ppm}$. The first cool-down started on Feb. 23, and finished on Mar. 22. The coils and the supporting structures were cooled by the temperature controlled helium gas, which was supplied by mixing cold gas and warm gas in the He refrigerator. When the supply gas temperature was higher than $80 \mathrm{~K}$, the cold He gas was generated with a liquid nitrogen heat exchanger $\left(\mathrm{LN}_{2}-\mathrm{HX} 15\right)$. Then the $\mathrm{LN}_{2}-\mathrm{HX}$ was stopped and the seven turbines $(\mathrm{Tl}-\mathrm{T} 7)$ in the He refrigerator were started in turn to produce the cold gas lower than $80 \mathrm{~K}$.

The helical coils became superconducting state on Mar. 17 at 16:10, while all poloidal coils became superconducting state at 22:58, as the supply gas temperature was $8.5 \mathrm{~K}$ and the coil outlet temperature was $9.0 \mathrm{~K}$. According to the

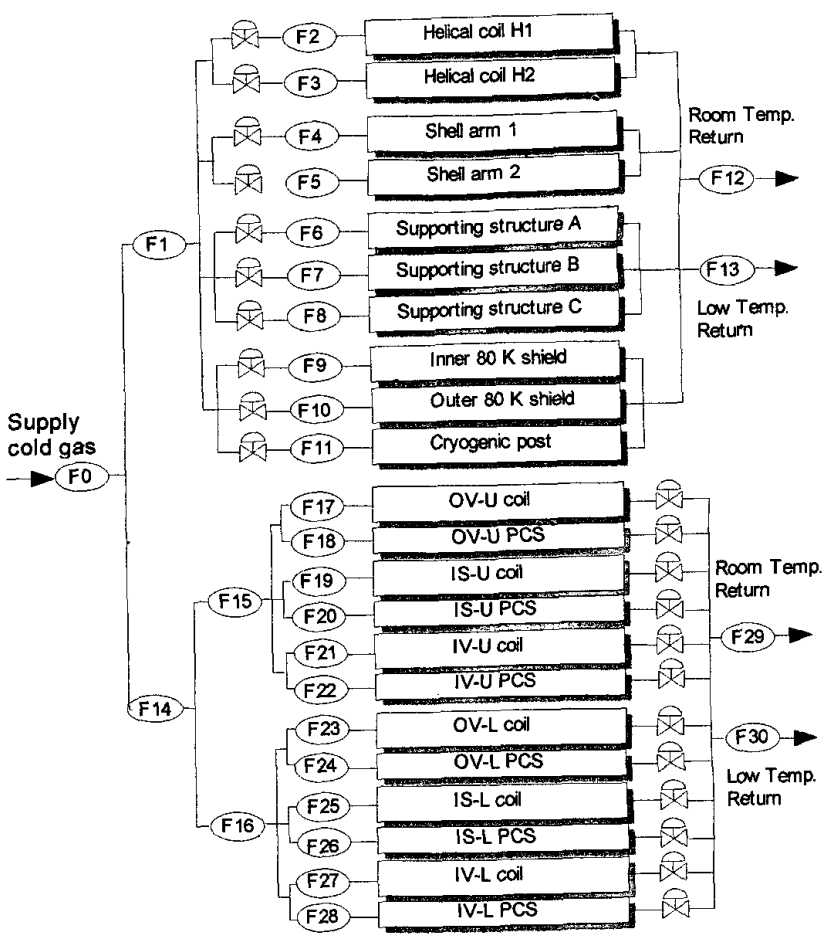

Fig.4. Parallel flow paths of the LHD cooling objects.

TABLE 2. FIRST CYCLE OPERATION OF THE LHD

\begin{tabular}{|c|c|c|}
\hline & Date & Events \\
\hline & $2 / 9-2 / 22$ & Purification \\
\hline & $2 / 9$ & Start He Compressors \\
\hline & $2 / 23-3 / 22$ & Cool-down \\
\hline (1) & $2 / 23$ & Cool-down process start \\
\hline \multirow[t]{2}{*}{ (2) } & $2 / 23-3 / 8$ & Cool-down with $\mathrm{LN}_{2}$-HX15 \\
\hline & $3 / 9-3 / 18$ & Cool-down with Turbines \\
\hline (3) & 3/9 & $\begin{array}{l}\text { Start Turbines T1 to T5 } \\
\text { Change flow of } 80 \mathrm{~K} \text { shield line }\end{array}$ \\
\hline (4) & $3 / 13$ & Start Turbines $\mathrm{T} 6$ and $\mathrm{T} 7$ \\
\hline (5) & $3 / 17$ & $\begin{array}{l}\text { Helical and Poloidal Coils } \\
\text { became superconducting state }\end{array}$ \\
\hline (6) & $3 / 18$ & SC Bus-lines became superconducting state \\
\hline \multirow[t]{8}{*}{ (7) } & $3 / 18-3 / 22$ & $\begin{array}{l}\text { Cooling paths of Helical coil \& Supporting } \\
\text { structure changed }\end{array}$ \\
\hline & & Cool-down with $\mathrm{LHe}$ \\
\hline & $3 / 23-3 / 28$ & Excitation Tests of $S C$ coils $(<=1.5 \mathrm{~T})$ \\
\hline & $3 / 29-5 / 17$ & Steady Operation for 1st Cycle Experiment \\
\hline & $3 / 31$ & First Plasma of the LHD Experiment \\
\hline & $5 / 14-5 / 15$ & Excitation tests for the coil power supplies \\
\hline & $5 / 18$ & $\begin{array}{l}\text { Emergency Discharge Tests of SC Coils (1.0 } \\
\text { T) }\end{array}$ \\
\hline & $5 / 19-6 / 15$ & Warm-up \\
\hline
\end{tabular}

program, the cool-down was successfully completed within 4 weeks on schedule.

After the cool-down, the excitation tests of the SC coils were successfully carried out up to $1.5 \mathrm{~T}$, which was the operating plasma central field during the first cycle experiments. The excitation tests of the $\mathrm{SC}$ coils up to the plasma central field of $3.0 \mathrm{~T}$ (nominal value) are planned at the end of 1998. 
The first plasma ignition of the LHD was marvelously operated on Mar. 31 without any delay from the schedule. The long-term operation for the first cycle plasma physics experiments have been conducted until May 17. On May 18, we conducted an emergency current discharging tests of the SC coils with a decay time constant of $20 \mathrm{sec}$ from the plasma central field of $1.0 \mathrm{~T}$. There was no serious reaction and the cryogenic system could continue to be operated in steady state. The whole cryogenic system was warmed up to the room temperature from May 19 to Jun. 15, as the opposite operation of the cool-down.

\section{B. First cool-down performance}

Fig. 5a shows the first cool-down curves of the LHD. The numbers in Fig. 5a corresponding to the events listed in Table 2. The helical coils, the poloidal coils, the supporting structure and the $80 \mathrm{~K}$ shield of the LHD cryostat were cooled with a small temperature deviation according to the supply gas temperature. Fig. $5 b$ shows the maximum temperature distribution in the cooling objects, which were controlled to be less than $50 \mathrm{~K}$. The supply gas temperature was decreased according to a programmed time chart, and was forced to pause when the maximum temperature
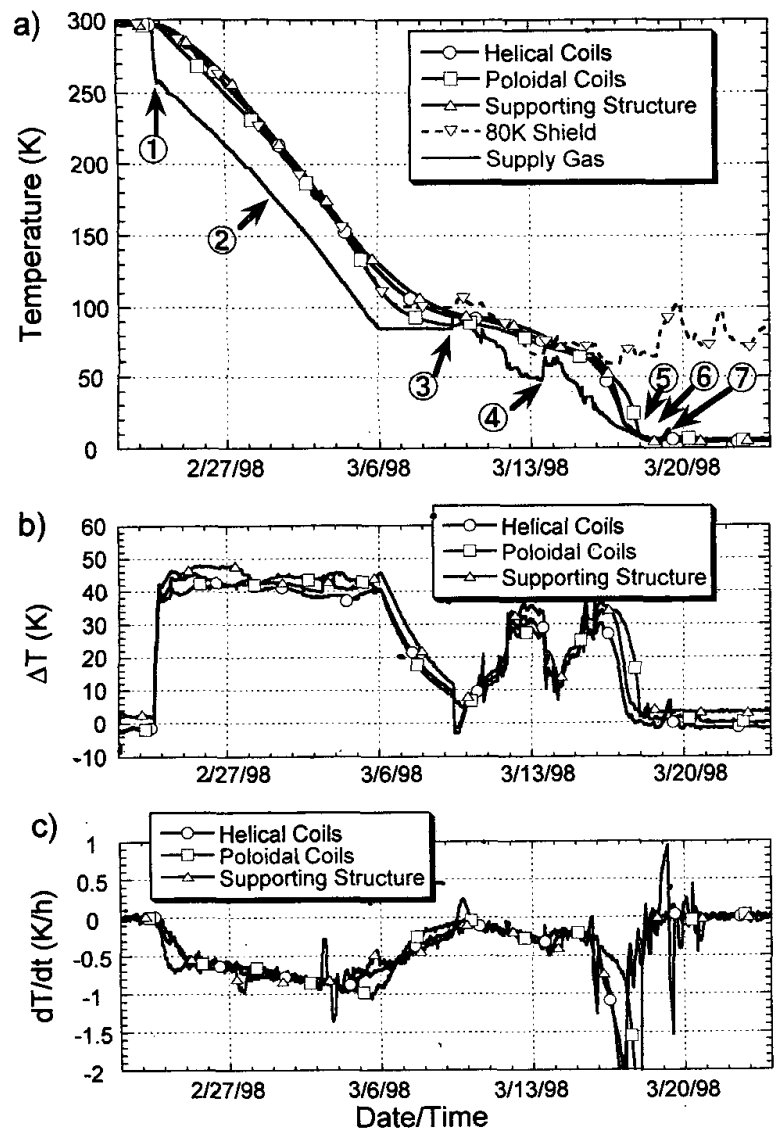

Fig. 5. a) First cool down curves of the LHD, b) Maximum temperature distribution in the cooling objects, c) Temperature gradient. distribution in the cooling objects exceeded $50 \mathrm{~K}$ by the temperature-distribution-watching program. Fig. $5 \mathrm{c}$ shows the temperature gradient for each cooling object. It can be seen in Fig. $5 b$ and $5 c$ that the maximum cooling rate has been achieved by keeping the limit $(50 \mathrm{~K})$ for the maximum temperature distribution.

\section{Controlled cool-down procedure}

Fig. 6 shows the mass flow rate of the total supply gas and the distributed mass flow rates for each cooling object. The total mass flow rate was restricted by conditions such as; pressure drops in the cooling objects, the transfer lines and the control valves; a limit of heat exchanger capacity, etc. After starting the turbines, the total mass flow rate was determined by a heat balance in the He refrigerator.

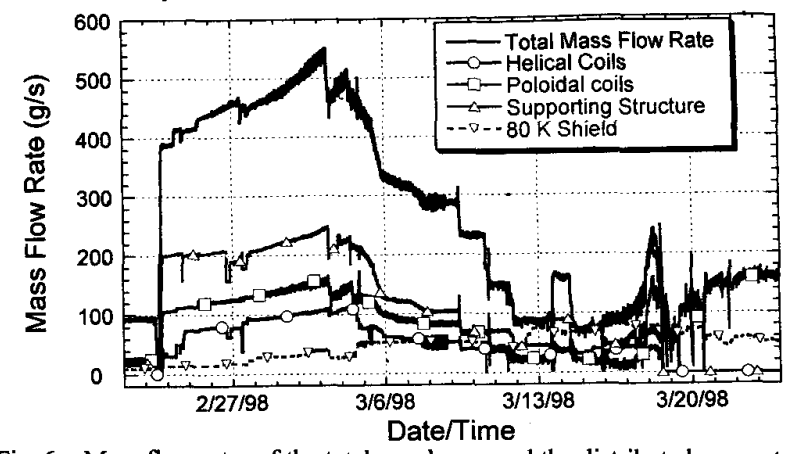

Fig. 6. Mass flow rates of the total supply gas and the distributed gasses to each cooling object.

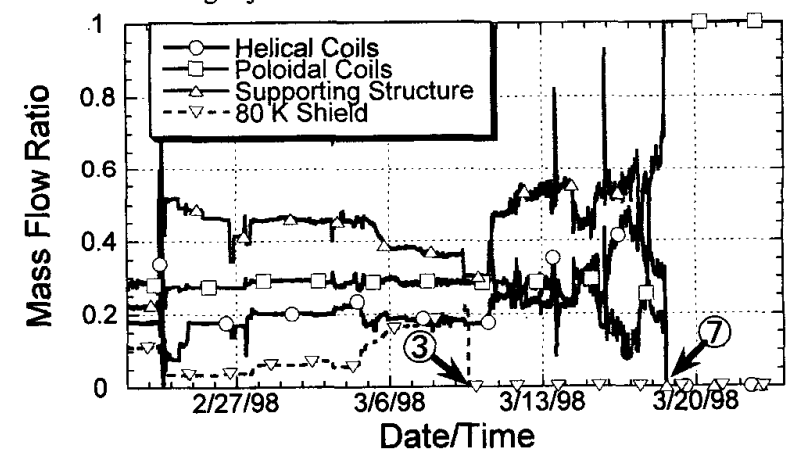

Fig. 7. Mass flow ratio; each mass flow rate divided by the total mass flow rate.

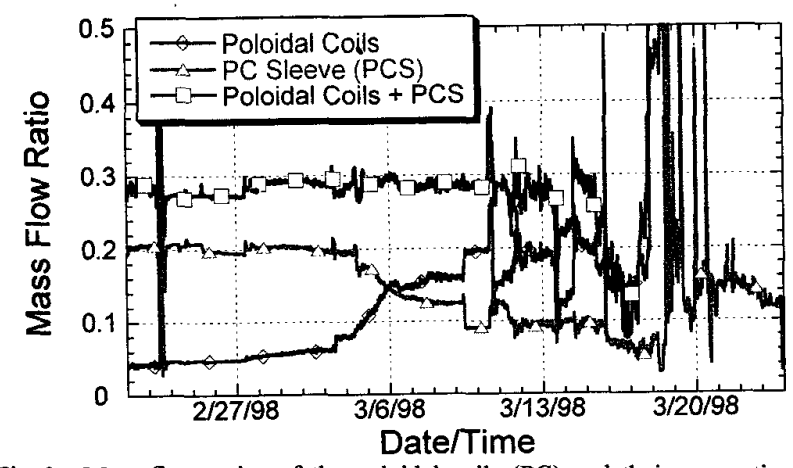

Fig. 8. Mass flow ratios of the poloidal coils (PC) and their supporting sleeves (PCS). 
To cool all objects at the same time with a small temperature deviation, we have controlled the ratios for each mass flow, which were initially determined according to the cold mass and were modified during the cool down process to reduce the temperature distribution in the cooling objects. Fig. 7 shows the mass flow ratios; each mass flow rate divided by the total mass flow rate. The ratios for the poloidal coils and the helical coils were kept almost constant before starting the turbines. The ratio for the supporting structure was decreased gradually according to the $80 \mathrm{~K}$ shield temperature, to increase the mass flow rate for the 80 $\mathrm{K}$ shield for compensating its steady heat in-leak.

Fig. 8 shows the mass flow ratios of the poloidal coils (PC) and their supporting sleeves (PCS). The pressure drops of the poloidal coils (forced-flow CICC coils without a cooling sub-channel in the conductor) are very high at the temperature higher than $150 \mathrm{~K}$. For example, the pressure drops of OV, IS and IV coils are $0.77 \mathrm{MPa}, 0.77 \mathrm{MPa}$ and $0.53 \mathrm{MPa}$ at each mass flow rate of $5.2 \mathrm{~g} / \mathrm{s}, 5.5 \mathrm{~g} / \mathrm{s}$ and 5.8 $\mathrm{g} / \mathrm{s}$, respectively at the coil outlet temperature of $200 \mathrm{~K}$. Therefore, the flow ratios of PCS were increased keeping the total ratio of the poloidal coils at the constant value. Then the coils were indirectly cooled by their PCS.

\section{Heat loads}

The measured heat loads are listed in Table 3 in comparison with the final design values. Owing to the extensive efforts of designing and developing each component, the total heat load became about half of the initial design value. The measured heat loads were almost the same as the final design value, which confirmed the validity of our design works and the proper construction procedures.

\begin{tabular}{|c|c|c|}
\hline Items & Design value & Measured value \\
\hline \multicolumn{3}{|l|}{ 4.4 K Refrigeration } \\
\hline Helical coils & $70 \mathrm{~W}$ & $87 \mathrm{~W}$ \\
\hline Supporting structure & $278 \mathrm{~W}$ & $148 \mathrm{~W}$ \\
\hline Poloidal coils total & $210 \mathrm{~W}$ & $217 \mathrm{~W}$ \\
\hline Superconducting bus-lines & $150 \mathrm{~W}$ & $145 \mathrm{~W}$ \\
\hline $\mathrm{H} / \mathrm{C} \& \mathrm{P} / \mathrm{C}$ valve box & $23 \mathrm{~W}$ & $\leftarrow(1)$ \\
\hline CL cryostat & $310 \mathrm{~W}$ & $\leftarrow(1)$ \\
\hline Transfer lines & 10 & $\mathrm{~W}^{(2)}$ \\
\hline $4.4 \mathrm{~K}$ total heat load & $2051 \mathrm{~W}$ & $1940 \mathrm{~W}$ \\
\hline \multicolumn{3}{|l|}{ 4.4 K Liquefaction } \\
\hline Current leads & $650 \mathrm{~L} / \mathrm{h}(3.0 \mathrm{~T})$ & $434 \mathrm{~L} / \mathrm{h}(1.5 \mathrm{~T})$ \\
\hline \multicolumn{3}{|l|}{$80 \mathrm{~K}$ Refrigeration } \\
\hline Inner $80 \mathrm{~K}$ shield & $5.54 \mathrm{~kW}$ & $3.36 \mathrm{~kW}$ \\
\hline Outer $80 \mathrm{~K}$ shield & $1.87 \mathrm{~kW}$ & $3.66 \mathrm{~kW}$ \\
\hline Cryogenic post & $0.82 \mathrm{~kW}$ & $0.80 \mathrm{~kW}$ \\
\hline $\mathrm{H} / \mathrm{C} \& \mathrm{P} / \mathrm{C}$ valve box & $1.14 \mathrm{~kW}$ & $1.12 \mathrm{~kW}$ \\
\hline Superconducting bus-lines & $1.50 \mathrm{~kW}$ & $1.15 \mathrm{~kW}$ \\
\hline CL cryostat & $0.62 \mathrm{~kW}$ & $0.54 \mathrm{~kW}$ \\
\hline Transfer lines & \multicolumn{2}{|c|}{$1.5 \mathrm{~kW}^{(2)}$} \\
\hline $80 \mathrm{~K}$ total heat loads & $12.99 \mathrm{~kW}$ & $12.13 \mathrm{~kW}$ \\
\hline
\end{tabular}

(1) Not measured directly, using final design values for the sum of the total heat load.

(2) Estimated value from the measurements of the units before assembling.

\section{E. Reliable long-term operation}

The long-term steady state operation was carried out from Mar. 23 to May 18 without any critical troubles. The impurities in He gas were removed carefully before the cool down started. Even though, a turbine inlet filter (T1 - T3) was blocked by impurities twice (Mar. 17 and Mar. 23) during the cool down process. The turbine inlet filter could be recovered by warming it up without disturbing the cool down process with a help of the $\mathrm{LN}_{2}$ heat exchanger $\mathrm{HX}-15$. In steady state operation, however, there was no trouble due to the impurities, such as blocking of turbines or the coil inlet filters, choking of control valves, decrease of heat exchanger efficiency, etc.

Two short time interruptions of the steady state operation were inevitable to reset the LHD cryogenic control system (LHD-TESS) due to software bugs, which could not be checked thoroughly before the first cycle operation started because of the extremely tight schedule. The total halt time was only 47 minutes.

\section{SUMMARY}

The LHD cryogenic system demonstrated its high performance and reliability in the first cycle operation. The cooling characteristics were confirmed to be the same as the expected ones from the examination during the design stage. The first cool down was successfully completed within 4 weeks on schedule. All cooling objects were cooled with a small temperature deviation by controlling the mass flow rate ratios of the supplying cold gas. The total heat loads under steady state condition were $1940 \mathrm{~W}+434 \mathrm{~L} / \mathrm{h}(1.5 \mathrm{~T})$ at $4.4 \mathrm{~K}$ and $12.1 \mathrm{~kW}$ at $80 \mathrm{~K}$, which is in the same level as the final design values. The long-term steady state operation was carried for 8 weeks without any critical troubles.

\section{ACKNOWLEDGMENT}

The authors are indebted to many staffs in NIFS who joined and supported LHD as well as many collaborators from universities and national laboratories. The authors are also grateful to the Nippon Sanso Co., Ltd., the Hitachi Ltd., the Toshiba Co., Fuji Electronic Co., Ltd. for their efforts to construct the LHD and to conduct the first cycle operation.

\section{REFERENCES}

[1] O. Motojima, et al., "Large Helical Device Project for SC SteadyState Fusion Experiment," Proceedings of the $16^{\text {th }}$ ICEC/ICMC, pp. 725-734, 1997.

[2] S. Satoh et al., "Design and Construction of Cryogenic Components for LHD," Proceedings of the $16^{\text {th }}$ ICEC/ICMC, pp. 63-66, 1997.

[3] R. Maekawa, et al., "Operation Characteristics of the Helium Refrigerator with a Dummy Load Apparatus for the Large Helical Device," Advance in Cryogenic Engineering, Proceeding of CEC/ICMC 1997 in Portland, USA, to be published.

[4] T. Mito, et al., "Development of a Cryogenic System for the Large Helical Device," Advance in Cryogenic Engineering, Proceeding of CEC/ICMC 1997 in Portland, USA, to be published. 